\title{
MTHFR C677T (rs1801133) genetic polymorphism is associated with development risk of essential hypertension in the Turkish population
}

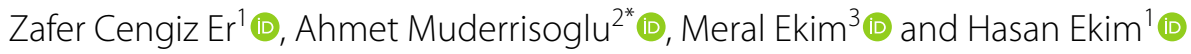

\begin{abstract}
Background: Hypertension is a serious condition that is spread worldwide and may lead to severe complications such as heart attack, stroke, hypertensive retinopathy, and renal failure. Although some genetic and environmental risk factors are known to play a role in the etiology of hypertension, like most of the other multi-factorial diseases, its etiology is yet to be fully elucidated. Our study aimed to investigate the effects of methylenetetrahydrofolate reductase (MTHFR) C677T (rs1801133) and A1298C (rs1801131), factor V Leiden (FVL) G1691A (rs6025), and prothrombin (PT) G20210A (rs1799963) genetic polymorphisms on the development risk of essential hypertension and level of blood pressure in hypertensive patients.

Results: The frequency of the homozygous polymorphic TT genotype for the MTHFR C677T polymorphism was significantly higher in male hypertensive patients than in the male control group ( $27 \% \mathrm{vs} 6.3 \%, p=0.028)$. The rate of the variant T allele for the MTHFR C677T polymorphism was also significantly higher in male hypertensive patients compared to male healthy controls (51.4\% vs $21.9 \%, p=0.0004)$. There was no difference among hypertensive patients and healthy controls regarding the frequencies of MTHFR A1298C, FVL G1691A and PT G20210A polymorphisms. In addition, we found no difference between genotype groups regarding systolic and diastolic blood pressure levels in hypertensive patients.
\end{abstract}

Conclusions: Homozygous polymorphic TT genotype and variant T allele for the MTHFR C677T polymorphism may be considered as a risk factor for the development of essential hypertension in the Turkish male population.

Keywords: MTHFR, FVL, PT, Essential hypertension, Polymorphism

\section{Background}

Hypertension is a serious condition that is spread worldwide and may lead to severe complications such as heart attack, stroke, hypertensive retinopathy, and renal failure [1]. It has been shown that essential hypertension is caused by various environmental and genetic factors [2]. Over the last decade, extensive efforts have been

\footnotetext{
*Correspondence: a.muderrisoglu@kku.edu.tr

${ }^{2}$ Department of Pharmacology, Faculty of Medicine, Kırıkkale University,

Kırıkkale, Turkey

Full list of author information is available at the end of the article
}

made to determine the genetic basis of essential hypertension. It has been suggested that hundreds of genetic polymorphisms involve in the pathogenesis of increased blood pressure [3]. Genome-related studies have identified some genetic loci associated with blood pressure [2]. Although some genetic and environmental risk factors are known to play a role in the etiology of hypertension, like most of the other multi-factorial diseases, its etiology is yet to be fully elucidated [4].

The methylenetetrahydrofolate reductase (MTHFR) gene is particularly involved in homocysteine and folate metabolism. It catalyzes 5,10-methylenetetrahydrofolate 
into 5-methyltetrahydrofolate, which serves as a methyl donor in the methionine synthase-driven conversion of homocysteine to methionine $[4,5]$. Methionine is then converted to S-adenosylmethionine, which can be used in some of the methylation reactions, including methylation of DNA, RNA, proteins, and other molecules [6]. The MTHFR C677T (rs1801133) polymorphism is a missense mutation that causes the substitution of alanine to valine in $222^{\text {th }}$ and $263^{\text {th }}$ positions of the amino acid sequence of methylenetetrahydrofolate reductase (NADPH) which results in functional loss [1]. Homozygous TT genotype carriers for the MTHFR C677T polymorphism have 30\% residual activity and heterozygous $\mathrm{CT}$ genotype carriers for the MTHFR C677T polymorphism have 70\% residual activity of the enzyme compared to wild type CC genotype carriers. Reduction of the enzyme activity may lead to hyperhomocysteinemia [7]. Reports have shown that mutations in the MTHFR gene are associated with an increased risk of cardiovascular disease as well as increased blood pressure [4]. Further, homozygous polymorphic TT genotype for the MTHFR C677T polymorphism is the only hereditary risk factor that has been identified to be associated with increased blood pressure [8]. Although, there are many studies in the literature that investigated the association between variants of MTHFR and development risk of essential hypertension, the results of these studies are not conclusive [4].

Factor V Leiden mutation (FVL G1691A; rs6025) is a missense mutation that is known to cause venous thromboembolism [9]. This variant leads to substitution of arginine to glycine at the $506^{\text {th }}$ position of the amino acid sequence of factor $\mathrm{V}$, one of the cleavage sites for activated protein $\mathrm{C}$ (APC). Thus, resulting in decreased level of inactivation of activated factor V by APC [10]. There are also studies in the literature that investigated the association between FVL G1691A polymorphism and increased blood pressure. Two previous meta-analysis study reported an association between $F V L$ G1691A polymorphism and hypertensive disorders of pregnancy $[11,12]$. Also, Demirel et al. and Makris et al. reported that there may be an association between the $F V L$ G1691A polymorphism and the development risk of essential hypertension [13, 14]. We encountered a small number of studies about $F V L$ G1691A polymorphism's effect on hypertension, especially in a healthy population other than pregnant women, in the literature. Therefore, further studies are needed to clarify the relationship between $F V L$ G1691A polymorphism and the development risk of essential hypertension.

Like the FVL G1691A polymorphism, PT G20210A (rs1799963) genetic polymorphism is known for its effect of elevating the risk of thrombosis [15]. It is located 3'-UTR region of the $P T F 2$ gene. It causes reduction in cleavage level of coagulation factor II to form thrombin and elevation of prothrombin levels [16]. The GenHAT study reported that in hypertensive patients who were using doxazosin for treatment, carriers of variant allele for the PT G20210A polymorphism were at a higher risk of developing coronary heart disease compared to wild-type allele carriers [17]. We encountered no study that investigated the association between PT G20210A polymorphism and development risk of essential hypertension in the literature. We thought that further investigation of this topic may be beneficial.

In this study, we aimed to investigate the effects of MTHFR C677T (rs1801133), MTHFR A1298C (rs1801131), FVL G1691A (rs6025), and PT G20210A (rs1799963) genetic polymorphisms on the development risk of essential hypertension. By doing so, we can contribute to the existing literature and help to clarify genetic risk factors for essential hypertension.

\section{Methods}

This study was conducted in the Department of Cardiovascular Surgery, Faculty of Medicine, Yozgat Bozok University between October 2016 and May 2018. Informed consent was obtained from participants, and the study protocol was approved by the Yozgat Bozok University Clinical Studies Ethics Committee (Protocol No: 14.10.2016/75).

A total of 140 participants were enrolled in this study (70 patients with essential hypertension and 70 healthy controls). Exclusion criteria were; having diabetes mellitus, renal insufficiency, and/or secondary hypertension. The participants were informed not to smoke cigarettes, drink tea or coffee within one hour before the physical examination. After resting for at least $10 \mathrm{~min}$, a standard sphygmomanometer was used to measure each participant's blood pressure two times in a sitting position on the dominant upper limb. A third blood pressure measurement was performed if there was a difference of more than $10 \mathrm{mmHg}$ in either the systolic or diastolic pressure values between the two measurements. The average of the closest two blood pressure measurements was used. Participants were diagnosed as having hypertension if they had a systolic arterial pressure greater than $140 \mathrm{mmHg}$ or a diastolic arterial pressure greater than $90 \mathrm{mmHg}$. All hypertensive patients had a history of hypertension but were not receiving any drug treatment by their choice. Subjects with systolic arterial pressure $\leq 120 \mathrm{mmHg}$ and diastolic arterial pressure $\leq 80 \mathrm{mmHg}$ were assigned to the control group.

Approximately $2 \mathrm{ml}$ of venous blood was taken from each participant's cubital vein into ethylenediaminetetraacetic acid (EDTA) tubes. DNA was extracted from the blood samples by using QIAamp DNA blood 
kit (Qiagen, Hilden, Germany). Previously described amplification refractory mutation system methods were used to identify MTHFR C677T (rs1801133) and MTHFR A1298C (rs1801131) polymorphisms [18]. Restriction fragment length polymorphism methods were used to identify FVL G1691A (rs6025) and $P T$ G20210A (rs1799963) polymorphisms [19]. Details of genotyping methods were shown at Additional file 1: Tables S1 and S2. A total volume of $25 \mathrm{ml}$ containing $200 \mathrm{mM}$ of each dATP, dCTP, dGTP, dTTP, $2.5 \mathrm{mM}$ $\mathrm{MgCl} 2, \mathrm{BSA}$, and $12.5 \mathrm{pmol}$ of each primer, 1 unit of Taq DNA Polymerase, and $100 \mathrm{ng}$ of genomic DNA used as a PCR mixture (Solis BioDyne, Tartu, Estonia). PCR conditions were; $94{ }^{\circ} \mathrm{C}$ for 2 min following 35 cycles of $94{ }^{\circ} \mathrm{C}$ for $20 \mathrm{~s}, 60{ }^{\circ} \mathrm{C}$ for $30 \mathrm{~s}, 72{ }^{\circ} \mathrm{C}$ for $1 \mathrm{~min}$, and $72{ }^{\circ} \mathrm{C}$ for $10 \mathrm{~min}$. PCR cycles were performed by a thermal cycler (Bio-Rad T100 Thermal Cycler, Bio-Rad Laboratories, Taipei, Taiwan). PCR products were separated by $3 \%$ agarose gel electrophoresis and visualized under UV light (Kodak, Rochester, NY, United States).

\section{Statistical analysis}

Blood pressure measurements and ages are presented as mean \pm standard deviation (SD). T-test was used to compare levels of systolic and diastolic blood pressure and age among groups. Genotype and allele frequencies of each polymorphism and gender were compared by using Chi-square and Fischer's exact tests where applicable. $p$ values $\leq 0.05$ were considered statistically significant. Statistical powers were calculated for the results that showed statistical significance by using PS Power and Sample Size Calculations computer program [20].

\section{Results}

The hypertensive group consisted of 37 males and 33 females with a mean age of $61.9 \pm 8.5$ years (range 45-78 years). Thirty-two males and 38 females with a mean age of $59.5 \pm 9.1$ years (range $38-74$ years) were in the control group. There were no statistically significant differences between hypertensive patients and healthy controls regarding age and gender.

Overall variant allele frequencies were $33.9 \%$ for the MTHFR C677T (rs1801133), 36.8\% for the MTHFR A1298C (rs1801131), 48.9\% for the FVL G1691A (rs6025) and $49.3 \%$ for the PT G20210A (rs1799963) genetic polymorphisms in our cohort of Turkish population. The distribution of all examined genetic polymorphisms was coherent with the Hardy-Weinberg equilibrium $(p>0.05)$.

The frequency of the homozygous polymorphic TT genotype for the MTHFR C677T polymorphism was significantly higher in male hypertensive patients than in the male control group ( $27 \%$ vs $6.3 \%, p=0.028$ ). The rate of the variant $\mathrm{T}$ allele for the MTHFR C677T polymorphism was also significantly higher in male hypertensive patients compared to male healthy controls $(51.4 \%$ vs $21.9 \%, p=0.0004)$ In contrast, there was no statistically significant difference among the groups about MTHFR C677T polymorphism in female participants. Frequencies of homozygous polymorphic TT genotype and variant $\mathrm{T}$ allele for the MTHFR C677T polymorphism were significantly higher in hypertensive patients than in controls when analyses were performed with two genders combined. Overall frequencies were $24.3 \%$ vs $8.6 \%$ for the TT genotype $(p=0.025)$ and $42.1 \%$ vs $25.7 \%$ for the $\mathrm{T}$ allele $(p=0.004)$ between hypertensive patients and healthy controls, respectively. Results were demonstrated in Table 1. Statistical powers were 0.602 and 0.684 for the

Table 1 Genotype and allele frequencies for the MTHFR C677T (rs1801133) polymorphism among groups

\begin{tabular}{|c|c|c|c|c|c|c|}
\hline & \multicolumn{3}{|c|}{ Genotype } & \multicolumn{2}{|l|}{ Allele } & \multirow{2}{*}{$\begin{array}{l}X^{2}, d f, p \\
\text { TT versus } C C+C T \\
C \text { versus } T\end{array}$} \\
\hline & CC: $n, \%$ & CT: $n, \%$ & TT: $n, \%$ & C: $n, \%$ & $\mathrm{~T}: n, \%$ & \\
\hline \multicolumn{7}{|l|}{ Male } \\
\hline Hypertensive Patients & $9,24.3$ & $18,48.6$ & 10,27 & $36,48.6$ & $38,51.4$ & $0.028^{*}$ \\
\hline Healthy Controls & $20,62.5$ & $10,31.3$ & $2,6.3$ & $50,78.1$ & $14,21.9$ & $12.7,1, \mathbf{0 . 0 0 0 4}$ \\
\hline \multicolumn{7}{|l|}{ Female } \\
\hline Hypertensive Patients & $19,57.6$ & $7,21.2$ & $7,21.2$ & $45,68.2$ & $21,31.8$ & $0.325^{*}$ \\
\hline Healthy Controls & $20,52.6$ & $14,36.8$ & $4,10.5$ & $54,71.1$ & $22,28.9$ & $0.138,1,0.71$ \\
\hline \multicolumn{7}{|l|}{ Total } \\
\hline Hypertensive Patients & 28,40 & $25,35.7$ & $17,24.3$ & $81,57.9$ & $59,42.1$ & $7.399,1, \mathbf{0 . 0 2 5}$ \\
\hline Healthy Controls & $40,57.1$ & $24,34.3$ & $6,8.6$ & $104,74.3$ & $36,25.7$ & $8.428,1, \mathbf{0 . 0 0 4}$ \\
\hline
\end{tabular}

Statistically significant $p$ values ( $>0.05$ ) were presented in bold for them to be distinguishable from the non-significant results

*Fischer's exact test 
genotype and allele analyses for the MTHFR C677T polymorphism, respectively.

We found no difference among the groups regarding MTHFR A1298C polymorphism. Homozygous polymorphic $\mathrm{CC}$ genotype and variant $\mathrm{C}$ allele frequencies were similar between the groups both in males and females. Likewise, there was no difference between the hypertensive group and the control group regarding MTHFR C677T-A1298C haplotypes (Data not shown.). Frequencies of genotypes and alleles for the MTHFR A1298C polymorphism are shown in Table 2.

Our results also showed that the risk of hypertension development was not associated with either $F V L$ G1691A or PT G20210A genetic polymorphisms. Genotype and allele frequencies for the FVL G1691A and $P T$ G20210A polymorphisms have shown in Tables 3 and 4, respectively.

Comparison between both systolic and diastolic blood pressures values among carriers of the homozygous wild-type, heterozygous and homozygous polymorphic genotypes for the MTHFR C677T, MTHFR A1298C,
FVL G1691A and PT G20210A genetic polymorphisms yielded no statistically significant different results in hypertensive patients. Systolic and diastolic blood pressure measurements among genotype groups are given in Table 5. There was also no difference between carriers of MTHFR haplotypes regarding mean systolic and diastolic blood pressures in hypertensive patients (Data not shown.).

\section{Discussion}

Hypertension is a widespread multicausal disease involving both genetic and environmental factors. It is an independent risk factor for cardiovascular disease [4]. Increased blood pressure can lead to serious complications such as stroke, renal failure, hypertensive retinopathy, and heart failure [21]. Lifestyle factors are reported to contribute to the development of high blood pressure. Also, genome-related studies have identified some genetic loci associated with blood pressure [2]. We found that homozygous polymorphic TT genotype and variant $\mathrm{T}$ allele for the MTHFR C677T polymorphism

Table 2 Genotype and allele frequencies for the MTHFR A1298C (rs1801131) polymorphism among groups

\begin{tabular}{|c|c|c|c|c|c|c|}
\hline & \multicolumn{3}{|c|}{ Genotype } & \multicolumn{2}{|l|}{ Allele } & \multirow{2}{*}{$\begin{array}{l}X^{2}, d f, p \\
\text { CC versus } A A+A C \\
\text { A versus } C\end{array}$} \\
\hline & AA: $n, \%$ & AC: $n, \%$ & CC: $n, \%$ & $A: n, \%$ & C: $n, \%$ & \\
\hline \multicolumn{7}{|l|}{ Male } \\
\hline Hypertensive Patients & 10,27 & $21,56.8$ & $6,16.2$ & $41,55.4$ & $33,44.6$ & $1^{*}$ \\
\hline Healthy Controls & $11,34.4$ & 16,50 & $5,15.6$ & $38,59.4$ & $26,40.6$ & $0.221,1,0.47$ \\
\hline \multicolumn{7}{|l|}{ Female } \\
\hline Hypertensive Patients & $19,57.6$ & $11,33.3$ & $3,9.1$ & $49,74.2$ & $17,25.8$ & $1^{*}$ \\
\hline Healthy Controls & $15,39.5$ & 19,50 & $4,10.5$ & $49,64.5$ & $27,35.5$ & $1.576,1,0.209$ \\
\hline \multicolumn{7}{|l|}{ Total } \\
\hline Hypertensive Patients & $29,41.4$ & $32,45.7$ & $9,12.9$ & $90,64.3$ & $50,35.7$ & $0,1,1$ \\
\hline Healthy Controls & $26,37.1$ & 35,50 & $9,12.9$ & $87,62.1$ & $53,37.9$ & $0.138,1,0.71$ \\
\hline
\end{tabular}

*Fischer's exact test

Table 3 Genotype and allele frequencies for the FVL G1691A (rs6025) polymorphism among groups

\begin{tabular}{|c|c|c|c|c|c|c|}
\hline & \multicolumn{3}{|l|}{ Genotype } & \multicolumn{2}{|l|}{ Allele } & \multirow{2}{*}{$\begin{array}{l}x^{2}, d f, p \\
A A \text { versus GG }+G A \\
G \text { versus } A\end{array}$} \\
\hline & GG: $n, \%$ & $\mathrm{GA}: n, \%$ & AA: $n, \%$ & $\mathrm{G}: n, \%$ & A: $n, \%$ & \\
\hline \multicolumn{7}{|l|}{ Male } \\
\hline Hypertensive Patients & $13,35.1$ & $11,29.7$ & $13,35.1$ & 37,50 & 37,50 & $0.042,1,0.839$ \\
\hline Healthy Controls & $13,40.6$ & $7,21.9$ & $12,37.6$ & $33,51.6$ & $31,48.4$ & $0.034,1,0.855$ \\
\hline \multicolumn{7}{|l|}{ Female } \\
\hline Hypertensive Patients & $15,45.6$ & $4,12.1$ & $14,42.4$ & $34,51.5$ & $32,48.5$ & $0.0007,1,0.978$ \\
\hline Healthy Controls & $17,44.7$ & $5,13.2$ & $16,42.1$ & $39,51.3$ & $37,48.7$ & $0.0006,1,0.981$ \\
\hline \multicolumn{7}{|l|}{ Total } \\
\hline Hypertensive Patients & 28,40 & $15,21.4$ & $27,38.6$ & $71,50.7$ & $69,49.3$ & $0.03,1,0.863$ \\
\hline Healthy Controls & $30,42.9$ & $12,17.1$ & 28,40 & $72,51.4$ & $68,48.6$ & $0.014,1,0.905$ \\
\hline
\end{tabular}


Table 4 Genotype and allele frequencies for the PT G20210A (rs1799963) polymorphism among groups

\begin{tabular}{|c|c|c|c|c|c|c|}
\hline & \multicolumn{3}{|l|}{ Genotype } & \multicolumn{2}{|l|}{ Allele } & \multirow{2}{*}{$\begin{array}{l}x^{2}, d f, p \\
A A \text { versus } G G+G A \\
G \text { versus } A\end{array}$} \\
\hline & GG: $n, \%$ & $\mathrm{GA}: n, \%$ & AA: $n, \%$ & $\mathrm{G}: n, \%$ & $A: n, \%$ & \\
\hline \multicolumn{7}{|l|}{ Male } \\
\hline Hypertensive patients & $17,45.9$ & $4,10.8$ & $16,43.2$ & $38,51.4$ & $36,48.6$ & $0.092,1,0.762$ \\
\hline Healthy controls & $15,46.9$ & $2,6.3$ & $15,46.9$ & 32,50 & 32,50 & $0.025,1,0.874$ \\
\hline \multicolumn{7}{|l|}{ Female } \\
\hline Hypertensive patients & $16,48.5$ & $2,6.1$ & $15,45.5$ & $34,51.5$ & $32,48.5$ & $0.026,1,0.872$ \\
\hline Healthy controls & $18,47.4$ & $2,5.3$ & $18,47.4$ & 38,50 & 38,50 & $0.032,1,0.857$ \\
\hline \multicolumn{7}{|l|}{ Total } \\
\hline Hypertensive patients & $33,47.1$ & $6,8.6$ & $31,44.3$ & $72,51.4$ & $68,48.6$ & $0.115,1,0.734$ \\
\hline Healthy controls & $33,47.1$ & $4,5.7$ & $33,47.1$ & 70,50 & 70,50 & $0.057,1,0.811$ \\
\hline
\end{tabular}

was associated with the risk of essential hypertension in our cohort of the Turkish male population. However, there were no differences between genotype groups for the MTHFR C677T polymorphism in hypertensive patients about levels of systolic and diastolic blood pressures. MTHFR A1298C, FVL G1691A and PT G20210A genetic polymorphisms were associated with neither risk of essential hypertension nor level of blood pressure in hypertensive patients. The same results were also found for the MTHFR haplotypes.

The frequency of the homozygous mutant TT genotype for the MTHFR C677T polymorphism was found to be $4 \%-18 \%$ in the US, $20 \%$ in Northern China, $26 \%$ in Southern Italy, and up to $32 \%$ in Mexico and $10 \%$ worldwide [22]. We found that the overall rate of the homozygous mutant TT genotype for the MTHFR C677T polymorphism was to be $16.4 \%$ in our cohort of the Turkish population.

Previous studies have suggested that homozygous mutant TT genotype for the MTHFR C677T polymorphism may be an independent risk factor for the development of early atherosclerotic organ damage in hypertensive patients [23]. Previous studies also indicated that the MTHFR C677T polymorphism was associated with both risks of essential hypertension and stroke [8]. Heux et al. reported that the MTHFR C677T polymorphism, which may cause mild hyperhomocysteinemia, may also cause an increased risk for essential hypertension [5]. Nassereddine et al. and Ilhan et al. reported that the homozygous polymorphic TT genotype for the MTHFR C677T polymorphism may be an independent risk factor for the development of essential hypertension $[4,24]$. A similar result was also found by Bayramoglu et al. [1]. Furthermore, a meta-analysis study reported an association between TT genotype for the MTHFR C677T polymorphism and the development of essential hypertension in various populations [25]. In contrast, an Algerian study reported no association between the MTHFR C677T polymorphism and essential hypertension [26]. Wu et al. found that the TT genotype for the MTHFR C677T polymorphism was associated with preeclampsia [27], while Yang et al. revealed that the same genotype was associated with both essential hypertension and pregnancy-related hypertension [3]. However, neither of these studies found an association between the MTHFR C677T polymorphism and essential hypertension [3]. The differing results among these studies may be due to the epigenetic mechanisms involved in the expression of the MTHFR gene, which can be influenced by environmental conditions such as lifestyle and diet [26]. In addition, some studies that have reported an association between elevated homocysteine levels and hypertension, also reported that interventions, which aimed to lower homocysteine levels, did not decrease blood pressure levels [8]. Considering the findings of the previous studies, it is likely that the homozygous mutant TT genotype for the MTHFR C677T polymorphism is associated with elevated blood pressure through a mechanism independent of homocysteine metabolism [8]. Similarly, our study showed that homozygous mutant TT genotype and polymorphic $\mathrm{T}$ allele for the MTHFR C677T genetic polymorphism was associated with the risk of essential hypertension in male hypertensive patients but not in female hypertensive patients (Table 1).

Horigan et al. reported significantly higher arterial pressure in hypertensive patients with TT genotype for the MTHFR C677T polymorphism [28]. Biochemical studies have shown that the decreased enzymatic activity in TT genotype carriers for the MTHFR C677T polymorphism leads to a decrease in the riboflavin cofactor (flavin adenine dinucleotide) [29]. And, riboflavin supplements have been reported to provide effective and wellcontrolled blood pressure in hypertensive patients with the TT genotype for the MTHFR C677T polymorphism 
Table 5 Comparison of both systolic and diastolic blood pressure values among genotype groups for the MTHFR C677T (rs1801133), MTHFR A1298C (rs1801131), FVL G1691A (rs6025) and PT G20210A (rs1799963) polymorphisms in hypertensive patients

\begin{tabular}{|c|c|c|c|c|}
\hline $\begin{array}{l}\text { Genetic } \\
\text { polymorphism }\end{array}$ & Genotype & $\begin{array}{l}\text { Systolic } \\
\text { blood } \\
\text { pressure }\end{array}$ & $\begin{array}{l}\text { Diastolic } \\
\text { blood } \\
\text { pressure }\end{array}$ & $p$ values \\
\hline \multicolumn{5}{|l|}{ Male } \\
\hline \multirow{3}{*}{$\begin{array}{l}\text { MTHFR } \\
\text { C677T }\end{array}$} & $\mathrm{CC}$ & $147 \pm 13.2$ & $98 \pm 10.4$ & \multirow{3}{*}{$\begin{array}{l}\text { SBP: } 0.253 \\
\text { DBP: } 0.458\end{array}$} \\
\hline & $\mathrm{CT}$ & $156 \pm 11.3$ & $102 \pm 8.2$ & \\
\hline & $T T$ & $171 \pm 10.5$ & $105 \pm 10.3$ & \\
\hline \multirow{3}{*}{$\begin{array}{l}\text { MTHFR } \\
\text { A1298C }\end{array}$} & AA & $150 \pm 10.1$ & $96 \pm 7.6$ & \multirow{3}{*}{$\begin{array}{l}\text { SBP: } 0.789 \\
\text { DBP: } 0.869\end{array}$} \\
\hline & $A C$ & $152 \pm 7.2$ & $98 \pm 4.8$ & \\
\hline & CC & $154 \pm 8.6$ & $99 \pm 10.8$ & \\
\hline \multirow{3}{*}{$\begin{array}{l}F V L \\
\text { G1691A }\end{array}$} & GG & $151 \pm 12.1$ & $93 \pm 8.4$ & \multirow{3}{*}{$\begin{array}{l}\text { SBP: } 0.756 \\
\text { DBP: } 0.654\end{array}$} \\
\hline & GA & $154 \pm 8.4$ & $95 \pm 6.8$ & \\
\hline & AA & $156 \pm 10.2$ & $98 \pm 9.6$ & \\
\hline \multirow{3}{*}{$\begin{array}{l}\text { PT } \\
\text { G20210A }\end{array}$} & GG & $149 \pm 11.2$ & $93 \pm 8.2$ & \multirow{3}{*}{$\begin{array}{l}\text { SBP: } 0.648 \\
\text { DBP: } 0.563\end{array}$} \\
\hline & GA & $151 \pm 8.9$ & $95 \pm 5.3$ & \\
\hline & $\mathrm{AA}$ & $156 \pm 7.5$ & $97 \pm 9.1$ & \\
\hline \multicolumn{5}{|l|}{ Female } \\
\hline \multirow{3}{*}{$\begin{array}{l}\text { MTHFR } \\
\text { C677T }\end{array}$} & $\mathrm{CC}$ & $141 \pm 8.8$ & $92 \pm 7.6$ & \multirow{3}{*}{$\begin{array}{l}\text { SBP: } 0.784 \\
\text { DBP: } 0.987\end{array}$} \\
\hline & $\mathrm{CT}$ & $150 \pm 8.9$ & $97 \pm 5.6$ & \\
\hline & $\mathrm{TT}$ & $165 \pm 10.2$ & $101 \pm 7.4$ & \\
\hline \multirow{3}{*}{$\begin{array}{l}\text { MTHFR } \\
\text { A1298C }\end{array}$} & AA & $146 \pm 6.4$ & $92 \pm 5.7$ & \multirow{3}{*}{$\begin{array}{l}\text { SBP: } 0.986 \\
\text { DBP: } 0.963\end{array}$} \\
\hline & $A C$ & $148 \pm 7.2$ & $93 \pm 3.6$ & \\
\hline & $\mathrm{CC}$ & $148 \pm 8.6$ & $95 \pm 5.8$ & \\
\hline \multirow{3}{*}{$\begin{array}{l}F V L \\
\text { G1691A }\end{array}$} & GG & $146 \pm 8.4$ & $91 \pm 7.3$ & \multirow{3}{*}{$\begin{array}{l}\text { SBP: } 0.853 \\
\text { DBP: } 0.954\end{array}$} \\
\hline & GA & $148 \pm 9.2$ & $92 \pm 7.8$ & \\
\hline & AA & $151 \pm 8.3$ & $94 \pm 8.6$ & \\
\hline \multirow{3}{*}{$\begin{array}{l}\text { PT } \\
\text { G20210A }\end{array}$} & GG & $144 \pm 7.4$ & $91 \pm 0.8$ & \multirow{3}{*}{$\begin{array}{l}\text { SBP: } 0.742 \\
\text { DBP:0.994 }\end{array}$} \\
\hline & GA & $146 \pm 8.6$ & $92 \pm 3.4$ & \\
\hline & $\mathrm{AA}$ & $151 \pm 7.6$ & $94 \pm 6.2$ & \\
\hline \multicolumn{5}{|l|}{ Total } \\
\hline \multirow{3}{*}{$\begin{array}{l}\text { MTHFR } \\
\text { C677T }\end{array}$} & $\mathrm{CC}$ & $147 \pm 13.2$ & $98 \pm 10.4$ & \multirow{3}{*}{$\begin{array}{l}\text { SBP: } 0.253 \\
\text { DBP: } 0.458\end{array}$} \\
\hline & $\mathrm{CT}$ & $156 \pm 11.3$ & $102 \pm 8.2$ & \\
\hline & $\mathrm{TT}$ & $171 \pm 10.5$ & $105 \pm 10.3$ & \\
\hline \multirow{3}{*}{$\begin{array}{l}\text { MTHFR } \\
\text { A1298C }\end{array}$} & $\mathrm{AA}$ & $150 \pm 10.1$ & $96 \pm 7.6$ & \multirow{3}{*}{$\begin{array}{l}\text { SBP: } 0.789 \\
\text { DBP: } 0.869\end{array}$} \\
\hline & $A C$ & $152 \pm 7.2$ & $98 \pm 4.8$ & \\
\hline & $\mathrm{CC}$ & $154 \pm 8.6$ & $99 \pm 10.8$ & \\
\hline \multirow{3}{*}{$\begin{array}{l}\text { FVL } \\
\text { G1691A }\end{array}$} & GG & $151 \pm 12.1$ & $93 \pm 8.4$ & \multirow{3}{*}{$\begin{array}{l}\text { SBP: } 0.756 \\
\text { DBP: } 0.654\end{array}$} \\
\hline & GA & $154 \pm 8.4$ & $95 \pm 6.8$ & \\
\hline & AA & $156 \pm 10.2$ & $98 \pm 9.6$ & \\
\hline \multirow{3}{*}{$\begin{array}{l}\text { PT } \\
\text { G20210A }\end{array}$} & GG & $149 \pm 11.2$ & $93 \pm 8.2$ & \multirow{3}{*}{$\begin{array}{l}\text { SBP: } 0.648 \\
\text { DBP: } 0.563\end{array}$} \\
\hline & GA & $151 \pm 8.9$ & $95 \pm 5.3$ & \\
\hline & $\mathrm{AA}$ & $156 \pm 7.5$ & $97 \pm 9.1$ & \\
\hline
\end{tabular}

Results are shown as mean \pm standard deviation

Systolic Blood Pressure: SBP

Diastolic Blood Pressure: DBP
[29]. We found that the levels of both systolic and diastolic blood pressure values were higher in the homozygous polymorphic TT genotype carriers. However, this difference did not reach statistical significance (Table 5). Results of the aforementioned studies suggest that hypertensive patients with TT genotype carriers for the MTHFR C677T polymorphism should eat riboflavin-rich foods to help regulate their blood pressure, our findings did not support this suggestion.

Carriers of TT genotype for the MTHFR C677T polymorphism appeared to have increased homocysteine levels, especially in cases with insufficient folate intake. Unlike the MTHFR C677T polymorphism, the elevation of homocysteine levels in homozygous polymorphic CC genotype carriers for the MTHFR A1298C polymorphism was not detected [30]. Wu et al. reported that the MTHFR C677T polymorphism was associated with the development of essential hypertension, while they found no association between the MTHFR A1298C polymorphism and the development of essential hypertension [31]. Likewise, our study showed no association between the MTHFR A1298C polymorphism and the risk of essential hypertension (Table 2).

FVL G1691A polymorphism was found to be associated with hypertensive disorders of pregnancy [11, 12]. Further, Demirel et al. reported that the frequency of the homozygous polymorphic genotype for the $F V L$ G1691A polymorphism was significantly higher in hypertensive patients compared to healthy individuals [13]. Also, Macris et al. found that the FVL G1691A polymorphism was associated with a history of myocardial infarction or essential hypertension [14]. Unlike the results of the mentioned studies, our study revealed no association of $F V L$ G1691A polymorphism with either development risk of essential hypertension in a healthy population or level of blood pressure in hypertensive patients. Aforementioned studies revealed that, aside from pregnant women, $F V L$ G1691A polymorphism's effect on hypertension is not clear. FVL G1691A polymorphism is known for its effect of elevating the risk of thromboembolism [9]. And, pregnant women with preeclampsia or eclampsia are at a higher risk of developing thromboembolic diseases such as ischemic stroke due to activation of the fibrinolytic system [32]. FVL G1691A polymorphism may contribute to increased blood pressure in hypertensive disorders of pregnancy by a mechanism yet to be fully elucidated [33]. However, FVL G1691A polymorphism's effect of increase in blood pressure is seem to be limited with preeclampsia and eclampsia [12]. Our finding of no association between $F V L$ G1691A polymorphism and development risk of essential hypertension may be the result of that.

Higgins et al. reported that there was no association between the PT G20210A polymorphism and 
hypertension in pregnant women [34]. In light of their finding, the authors suggested that there is no need for routine testing for the $P T$ G20210A polymorphism in pregnant women with pre-eclampsia [34]. However, another polymorphism that found to be associated with venous thromboembolism risk; 4G/5G deletion/insertion polymorphism of plasminogen activator inhibitor 1 gene (PAI-1) [35], was identified as an independent risk factor for hypertension in Korean women [36]. PAI-1 is responsible for the primary inhibition of tissue-type plasminogen activator [37]. In light of the mentioned studies, it seems that PT G20210A polymorphism's effect on hypertension has not been clearly shown. In that sense, our finding of no association of PT G20210A polymorphism with essential hypertension has the potential to contribute to the existing literature.

Our study was limited for not being able to measure plasma homocysteine levels to clearly determine the association between polymorphisms of MTHFR and increased blood pressure. Another of our limitations were the relatively small size of the study population and not exactly matching age range among hypertensive patients and healthy controls.

\section{Conclusions}

According to our results, polymorphic $\mathrm{T}$ allele for the MTHFR C677T (rs1801133) polymorphism may be considered as a genetic risk factor for the development of essential hypertension. With the results of further studies that support this finding, we suggest that MTHFR C677T polymorphism may be placed in genetic screening for the risk of essential hypertension.

\section{Abbreviations}

DBP: Diastolic blood pressure; EDTA: Ethylenediaminetetraacetic acid; FVL: Factor V Leiden; MTHFR: Methylenetetrahydrofolate reductase; PCR: Polymerase chain reaction; PT: Prothrombin; SBP: Systolic blood pressure; SD: Standard deviation.

\section{Supplementary Information}

The online version contains supplementary material available at https://doi. org/10.1186/s43042-022-00221-z.

Additional file 1. Details of the genotyping methods.

\section{Acknowledgements}

We acknowledge Kivanc Atilgan, M.D. for his contributions.

\section{Authors' contributions}

ZCE and AM: Wrote the paper; ZCE nd HE: Collected the data; ZCE, ME and HE: Organization; ZCE and AM: Translation and Statistics; ZCE, AM, ME and HE: Data analyze; ZCE and HE: Conceived the Project; All authors have read and approved the publication of the manuscript.

\section{Funding}

No funding was received.

\section{Availability of data and materials}

Not applicable. Ethics approval of this study does not content for sharing. It requires another ethics committee approval.

\section{Declarations}

Ethics approval and consent to participate

This study is made in accordance with the ethical standards of the institutional research committee and with the 1964 Helsinki Declaration and its later amendments or comparable ethical standards. Every participant provided informed written consent, and the study protocol was approved by the Yozgat Bozok University Clinical Studies Ethics Committee (Protocol No: 14.10.2016/75). Informed consent was obtained from all participants.

\section{Consent for publication}

Every participant provided informed consent, and assent for publication has taken from participants. The study protocol was approved by the Yozgat Bozok University Clinical Studies Ethics Committee (Protocol No: 14.10.2016/75).

\section{Competing interests}

The authors declare no conflict of interest.

\section{Author details}

${ }^{1}$ Department of Cardiovascular Surgery, Faculty of Medicine, Yozgat Bozok University, Yozgat, Turkey. ${ }^{2}$ Department of Pharmacology, Faculty of Medicine, Kırıkkale University, Kırıkkale, Turkey. ${ }^{3}$ Department of Emergency Aid and Disaster Management, Faculty of Health Sciences, Yozgat Bozok University, Yozgat, Turkey.

Received: 8 September 2021 Accepted: 29 November 2021

Published online: 17 January 2022

\section{References}

1. Bayramoglu A, Urhan Kucuk M, Guler HI, Abaci O, Kucukkaya Y, Colak E (2015) Is there any genetic predisposition of MMP-9 gene C1562T and MTHFR gene C677T polymorphisms with essential hypertension? Cytotechnology 67(1):115-122

2. McAuley E, McNulty H, Hughes C, Strain JJ, Ward M (2016) Riboflavin status, MTHFR genotype and blood pressure: current evidence and implications for personalised nutrition. Proc Nutr Soc 75(3):405-414

3. Yang B, Fan S, Zhi X, Li Y, Liu Y, Wang D et al (2014) Associations of MTHFR gene polymorphisms with hypertension and hypertension in pregnancy: a meta-analysis from 114 studies with 15411 cases and 21970 controls. PLOS ONE 9(2):e87497

4. Nassereddine S, Kassogue Y, Korchi F, Habbal R, Nadifi S (2015) Association of methylenetetrahydrofolate reductase gene (C677T) with the risk of hypertension in Morocco. BMC Res Notes 8:775

5. Heux S, Morin F, Lea RA, Ovcaric M, Tajouri L, Griffiths LR (2004) The methylentetrahydrofolate reductase gene variant (C677T) as a risk factor for essential hypertension in Caucasians. Hypertens Res 27(9):663-667

6. Ergul E, Sazci A, Kara I (2012) Methylenetetrahydrofolate reductase gene polymorphisms in Turkish children with attention-deficit/hyperactivity disorder. Genet Test Mol Biomark 16(1):67-69

7. Fridman O, Porcile R, Morales AV, Gariglio LO, Potenzoni MA, Turk Noceto PC (2013) Association of methylenetetrahydrofolate reductase gene 677C > T polymorphism with hypertension in older women in a population of Buenos Aires City. Clin Exp Hypertens 35(3):159-166

8. McNulty H, Strain JJ, Hughes CF, Ward M (2017) Riboflavin, MTHFR genotype and blood pressure: a personalized approach to prevention and treatment of hypertension. Mol Aspects Med 53:2-9

9. Klarin D, Emdin CA, Natarajan P, Conrad MF, INVENT Consortium, Kathiresan S (2017) Genetic analysis of venous thromboembolism in UK biobank identifies the ZFPM2 locus and implicates obesity as a causal risk factor. Circ Cardiovasc Genet 10(2):e001643

10. Zoller B, Svensson PJ, Dahlback B, Lind-Hallden C, Hallden C, Elf J (2020) Genetic risk factors for venous thromboembolism. Expert Rev Hematol 13(9):971-981 
11. Staines-Urias E, Paez MC, Doyle P, Dudbridge F, Serrano NC, loannidis JP et al (2012) Genetic association studies in pre-eclampsia: systematic meta-analyses and field synopsis. Int J Epidemiol 41(6):1764-1775

12. Li Y, Ruan Y (2019) Association of hypertensive disorders of pregnancy risk and factor $V$ Leiden mutation: a meta-analysis. J Obstet Gynaecol Res 45(7):1303-1310

13. Demirel Y, Dogan S, Uludag A, Silan C, Atik S, Silan F et al (2011) Combined effect of Factor $V$ Leiden, MTHFR, and angiotensin-converting enzyme (insertion/deletion) gene mutations in hypertensive adult individuals: a population-based study from Sivas and Canakkale, Turkey. Genet Test Mol Biomark 15(11):785-791

14. Makris TK, Krespi PG, Hatzizacharias AN, Gialeraki AE, Anastasiadis G, Triposkiadis FK et al (2000) Resistance to activated protein C and FV leiden mutation in patients with a history of acute myocardial infarction or primary hypertension. Am J Hypertens 13(1 Pt 1):61-65

15. Simone B, De Stefano V, Leoncini E, Zacho J, Martinelli I, Emmerich J et al (2013) Risk of venous thromboembolism associated with single and combined effects of Factor V Leiden, Prothrombin 20210A and Methylenetethraydrofolate reductase C677T: a meta-analysis involving over 11,000 cases and 21,000 controls. Eur J Epidemiol 28(8):621-647

16. Martinelli I, Bucciarelli P, Margaglione M, De Stefano V, Castaman G, Mannucci PM (2000) The risk of venous thromboembolism in family members with mutations in the genes of factor $\mathrm{V}$ or prothrombin or both. $\mathrm{Br} J$ Haematol 111(4):1223-1229

17. Lynch Al, Eckfeldt JH, Davis BR, Ford CE, Boerwinkle E, Leiendecker-Foster $C$ et al (2012) Gene panels to help identify subgroups at high and low risk of coronary heart disease among those randomized to antihypertensive treatment: the GenHAT study. Pharmacogenet Genom 22(5):355-366

18. Khidri FF, Waryah YM, Ali FK, Shaikh H, Ujjan ID, Waryah AM (2019) MTHFR and F5 genetic variations have association with preeclampsia in Pakistani patients: a case control study. BMC Med Genet 20(1):163

19. Kruse L, Mitchell AM, Camargo CA Jr, Hernandez J, Kline JA (2006) Frequency of thrombophilia-related genetic variations in patients with idiopathic pulmonary embolism in an urban emergency department. Clin Chem 52(6):1026-1032

20. Dupont WD, Plummer WD Jr (1990) Power and sample size calculations. A review and computer program. Control Clin Trials 11(2):116-128

21. Ghogomu SM, Ngolle NE, Mouliom RN, Asa BF (2016) Association between the MTHFR C677T gene polymorphism and essential hypertension in South West Cameroon. Genet Mol Res 15(1):28

22. Wilcken B, Bamforth F, Li Z, Zhu H, Ritvanen A, Renlund M et al (2003) Geographical and ethnic variation of the $677 \mathrm{C}>$ T allele of 5,10 methylenetetrahydrofolate reductase (MTHFR): findings from over 7000 newborns from 16 areas world wide. J Med Genet 40(8):619-625

23. Ravera M, Viazzi F, Berruti V, Leoncini G, Zagami P, Bezante GP et al (2001) 5,10-Methylenetetrahydrofolate reductase polymorphism and early organ damage in primary hypertension. Am J Hypertens 14(4 Pt 1):371-376

24. Ilhan N, Kucuksu M, Kaman D, Ilhan N, Ozbay Y (2008) The 677 C/T MTHFR polymorphism is associated with essential hypertension, coronary artery disease, and higher homocysteine levels. Arch Med Res 39(1):125-130

25. Yang KM, Jia J, Mao LN, Men C, Tang KT, Li YY et al (2014) Methylenetetrahydrofolate reductase C677T gene polymorphism and essential hypertension: a meta-analysis of 10,415 subjects. Biomed Rep 2(5):699-708

26. Amrani-Midoun A, Kiando SR, Treard C, Jeunemaitre X, Bouatia-Naji N (2016) The relationship between MTHFR C677T gene polymorphism and essential hypertension in a sample of an Algerian population of Oran city. Int J Cardiol 225:408-411

27. Wu X, Yang K, Tang X, Sa Y, Zhou R, Liu J et al (2015) Folate metabolism gene polymorphisms MTHFR C677T and A1298C and risk for preeclampsia: a meta-analysis. J Assist Reprod Genet 32(5):797-805

28. Horigan G, McNulty H, Ward M, Strain JJ, Purvis J, Scott JM (2010) Riboflavin lowers blood pressure in cardiovascular disease patients homozygous for the 677C $->$ T polymorphism in MTHFR. J Hypertens 28(3):478-486

29. Wilson CP, McNulty H, Ward M, Strain JJ, Trouton TG, Hoeft BA et al (2013) Blood pressure in treated hypertensive individuals with the MTHFR 677TT genotype is responsive to intervention with riboflavin: findings of a targeted randomized trial. Hypertension 61(6):1302-1308

30. Rady PL, Tyring SK, Hudnall SD, Vargas T, Kellner LH, Nitowsky H et al (1999) Methylenetetrahydrofolate reductase (MTHFR): the incidence of mutations C677T and A1298C in the Ashkenazi Jewish population. Am J Med Genet 86(4):380-384

31. Wu YL, Hu CY, Lu SS, Gong FF, Feng F, Qian ZZ et al (2014) Association between methylenetetrahydrofolate reductase (MTHFR) C677T/A1298C polymorphisms and essential hypertension: a systematic review and meta-analysis. Metabolism 63(12):1503-1511

32. Witcher PM, Chez BF, Baird SM (2015) Multisystem effects of hypertensive disorders of pregnancy: a comprehensive review. J Perinat Neonatal Nurs 29(3):229-239

33. Ali SM, Khalil RA (2015) Genetic, immune and vasoactive factors in the vascular dysfunction associated with hypertension in pregnancy. Expert Opin Ther Targets 19(11):1495-1515

34. Higgins JR, Kaiser T, Moses EK, North R, Brennecke SP (2000) Prothrombin G20210A mutation: is it associated with pre-eclampsia? Gynecol Obstet Investig 50(4):254-257

35. Zhang Q, Jin Y, Li X, Peng X, Peng N, Song J et al (2020) Plasminogen activator inhibitor-1 (PAI-1) 4G/5G promoter polymorphisms and risk of venous thromboembolism - a meta-analysis and systematic review. Vasa 49(2):141-146

36. Kim KN, Kim KM, Kim BT, Joo NS, Cho DY, Lee DJ (2012) Relationship of plasminogen activator inhibitor 1 gene $4 \mathrm{G} / 5 \mathrm{G}$ polymorphisms to hypertension in Korean women. Chin Med J (Engl) 125(7):1249-1253

37. UniProt. UniProtKB - P05121 (PAl1_HUMAN). 10 April 2018 ed2018

\section{Publisher's Note}

Springer Nature remains neutral with regard to jurisdictional claims in published maps and institutional affiliations.

\section{Submit your manuscript to a SpringerOpen ${ }^{\circ}$ journal and benefit from:}

- Convenient online submission

- Rigorous peer review

- Open access: articles freely available online

- High visibility within the field

- Retaining the copyright to your article

Submit your next manuscript at springeropen.com 